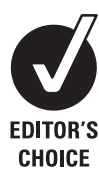

- Additional tables are published online only at http:// jech.bmj.com/content/vol63/ issue8

${ }^{1}$ Institute of Social and Preventive Medicine (ISPM), University of Zurich, Zurich, Switzerland; ${ }^{2}$ Institute of Social and Preventive Medicine, University of Bern, Bern, Switzerland

Correspondence to:

Dr M Bopp, University of Zurich, Institute of Social and Preventive Medicine, Hirschengraben 84 8001 Zürich, Switzerland; bopp@ifspm.uzh.ch

Accepted 23 February 2009

\title{
Culture, risk factors and mortality: can Switzerland add missing pieces to the European puzzle?
}

\author{
D Faeh, ${ }^{1}$ C Minder, ${ }^{2}$ F Gutzwiller, ${ }^{1}$ M Bopp,${ }^{1}$ for the Swiss National Cohort Study Group
}

\section{ABSTRACT}

Background: The aim was to compare cause-specific mortality, self-rated health (SRH) and risk factors in the French and German part of Switzerland and to discuss to what extent variations between these regions reflect differences between France and Germany.

Methods: Data were used from the general population of German and French Switzerland with 2.8 million individuals aged 45-74 years, contributing 176782 deaths between 1990 and 2000. Adjusted mortality risks were calculated from the Swiss National Cohort, a longitudinal census-based record linkage study. Results were contrasted with crosssectional analyses of SRH and risk factors (Swiss Health Survey 1992/3) and with cross-sectional national and international mortality rates for 1980, 1990 and 2000.

Results: Despite similar all-cause mortality, there were substantial differences in cause-specific mortality between Swiss regions. Deaths from circulatory disease were more common in German Switzerland, while causes related to alcohol consumption were more prevalent in French Switzerland. Many but not all of the mortality differences between the two regions could be explained by variations in risk factors. Similar patterns were found between Germany and France.

Conclusion: Characteristic mortality and behavioural differentials between the German- and the French-speaking parts of Switzerland could also be found between Germany and France. However, some of the international variations in mortality were not in line with the Swiss regional comparison nor with differences in risk factors. These could relate to peculiarities in assignment of cause of death. With its cultural diversity, Switzerland offers the opportunity to examine cultural determinants of mortality without bias due to different statistical systems or national health policies.

Substantial differences in mortality can be found between European countries. ${ }^{1}$ Comparing these differences could help to evaluate risk factors and the predictive power of self-rated health (SRH) in order to identify unexploited potentials for reduction in mortality. Unfortunately, there is a serious lack of internationally comparable data. ${ }^{2}$ The sample sizes in many European health surveys are small and longitudinal data on mortality are scarce and often not comparable. Many countries have only cross-sectional mortality data, which may be affected by numerator/denominator bias.

Another major problem of comparisons between countries is that it is difficult to determine whether differences in cause-specific mortality are real. It remains unknown how much of the international variation is not caused by corresponding differences in risk factors but is rather a result of variations in data collection and processing, of assignment of causes of death or of different definitions of risk factors or SRH. ${ }^{3-5}$ Moreover, little is known about the contribution of national health policies and healthcare systems to mortality differences.

Some of these limitations can be overcome by comparing variation in national mortality patterns with those found between culturally (with respect to language, lifestyle and attitudes) diverse populations within the same nation. This may offer a chance to trade off the influence of cultural against national factors and thus help to disentangle real prevention potentials from statistical artefacts. Switzerland offers a unique setting for the investigation of the relationship between mortality and risk factors because it combines cultural diversity with a common national health policy and a uniform statistical system. Thus, differences between populations representing the "German" and "French" type of cultures (eg, high and low adherence to a Mediterranean lifestyle) can be studied without bias due to differences in national health policies or statistical systems. Therefore, we hypothesise that Switzerland realistically mirrors variation patterns existing between the two largest European countries.

To assess this hypothesis, we analysed variations in mortality between the French and German parts of Switzerland and defined cultural affiliation by language. We included associated risk factors (including SRH) to estimate how much of the variation can be explained by cultural differences in behaviour. In order to investigate whether differences found between the Swiss regions reflect differences between Germany and France, we compared our results with available data from these countries.

\section{METHODS}

\section{Swiss National Cohort}

The Swiss National Cohort (SNC) is a national longitudinal research platform based on anonymous record linkage of data collected by the Swiss Federal Statistical Office. The core cohort consists of the 6.874 million residents who participated in the 1990 census. For 476814 individuals with a 1990 census record (6.9\%) no satisfactory link could be found. However, the majority of unlinked records related to individuals aged 10-29 years who were not included in our analysis (for more details see Bopp et $a l^{6}$ ). The 1990 and 2000 censuses in Switzerland were carried out with self-administered questionnaires. Non-participation is considered to be very low (for the 2000 census, coverage was estimated at $98.6 \%)^{7}$ Of all registered deaths between the 1990 and the 2000 census, $95.3 \%$ could be successfully linked to the SNC. ${ }^{8}$ For this study individuals were followed up in the period between 4 December 1990 and 5 December 2000 (census dates) and between the 
ages of 45 and 74 years. Deaths and person years were only accumulated in that age span. Thus, the youngest observed subject just had passed his 35th birthday on 4 December 1990 and contributed only 1 day of observation on 4 December 2000. Individuals aged 75 years and older at the 1990 census were excluded and those reaching their 75th birthday between the census dates were censored. Overall, we included all Swiss and foreign nationals who could be linked to a mortality or 2000 census record and lived in the German (GS, $\mathrm{n}=1417$ 571) and the French part of Switzerland (FS, $n=445205$ ), respectively. Because of too small cell sizes, we excluded the Italian part of the country $(<5 \%$ of total).

\section{Cross sectional mortality data}

Swiss mortality rates of the periods 1979-82, 1989-92, and 1999-2002 originate from the official mortality files of the Swiss Federal Statistical Office. Cause of death was coded centrally at the Federal Statistical Office. Except for the deaths of some foreign nationals that occurred abroad, mortality registration in Switzerland can be regarded as virtually complete. Mortality data by sex and 5 -year age class for Germany and France (in 1980, 1990 and 2000) were extracted from the World Health Organization (WHO) World Mortality Database (www.who. int/whosis/mort/en/index.html).

\section{Assessment of risk factors}

Data on SRH and risk factors stem from the first Swiss Health Survey (SHS) from 1992/3. The SHS is a cross-sectional, nationwide, population-based survey conducted every 5 years by the Swiss Federal Statistical Office to monitor public health trends. It consists of questions on health status and health behaviours asked of a random sample of persons aged 15 years and older living in Switzerland. Data were collected with a telephone interview and a self-administered questionnaire. Eligible subjects were chosen by stratified random sampling of a database of all private Swiss households with telephones. The survey was completed by 15288 participants (71\% participation rate, $52 \%$ women, for more details see Eichholzer et al ${ }^{9}$ ).

For this study, we limited the age range to $45-74$ years. This led to a total of 5739 people (57\% women). For SRH, possible answers for describing own health included "very good", "good", "fair", "poor", "very poor". The last three defined "less-than-good health". For simplicity, we defined only risk (and not protective) factors, with alcohol having positive and negative effects on health. Risk factors were defined as follows: "Current smoking" was defined when smoking $\geqslant 1$ cigarette/day; "daily alcohol consumption" when drinking alcohol at least once per day; "infrequent fruit consumption" when not eating fruits daily; "physical inactivity" when not sweating at least once per week by performing physical activity in leisure time. Obesity was defined as body mass index $\left.(=\text { weight } / \text { (height })^{2}\right) \geqslant 30 \mathrm{~kg} / \mathrm{m}^{2}$.

\section{Statistical analysis}

We transformed the individual data from the SNC into survivaltime data using the "st" commands of STATA. Mortality rates for 5-year age classes were obtained by using the "stsplit" command. Age standardised mortality rates (per 100000 person years) and $95 \%$ CIs of selected causes of death by region (GS and FS) and sex were obtained with the "dstdize" command.

Corresponding cross-sectional figures for German and French Switzerland were calculated from national mortality statistics 1979-82, 1989-92 and 1999-2002 (numerator) and data from the 1980, 1990 and 2000 census (denominator). Corresponding rates for France and Germany were calculated from the mortality and population figures 1980, 1990 and 2000 in the WHO Mortality Database. Data for 1980 and 1990 for Germany refer to the old Federal Republic of Germany.

All measures were adjusted for age by applying direct standardisation to the WHO Standard Population "Europe". ${ }^{10}$ For comparison of the SNC-based figures for 1990-2000 of GS and FS with Germany and France respectively, we used the mean of the 1990 and 2000 rates for the countries.

We performed analyses focusing on the main groups of causes of death (diseases of the circulatory system, cancer, other diseases and injuries). In addition to all-cancer mortality, we analysed separately cancers of the aerodigestive tract (UADT: oropharynx, larynx, oesophagus), stomach, intestine, liver, lung, prostate and female breast. Table A1 (available online) shows the ICD-8/9 and ICD-10 codes of selected causes of death. For Switzerland ICD-8 was used until 1994 (thereafter ICD-10). In Germany and France ICD-9 was in operation for 1980 and 1990 and ICD-10 for 2000.

For the analysis of the SHS data, we calculated percentages and $95 \%$ CIs using figures weighted to the Swiss population. All calculations and analyses were performed with STATA (version 9) SE (StataCorp, College Station, Texas), except cross-sectional mortality, which was calculated with SAS (version 6.12 for Macintosh; SAS Institute, Cary, North Carolina). p Values $<0.05$ were considered significant.

\section{RESULTS}

\section{Mortality in Swiss regions (from the SNC)}

Overall 1862776 people accumulating 20259818 person years were included: 675452 men and 742119 women from GS; 210201 men and 235004 women from FS. More details are shown in the appendix (see online table A2).

Table 1 shows the number of deaths and the death rates (per 100000 person years) with 95\% CIs by region and sex for selected causes of death. In men, all-cause mortality rates were somewhat higher in FS than in GS, whereas in women the opposite applied. The lower mortality from coronary heart disease (CHD) and stroke in FS men was overcompensated by other causes of death, notably cancer. The all-cause mortality advantage of FS over GS women results mainly from circulatory disease and cancer but also from other disease-related causes of death.

In both sexes, the lower circulatory disease mortality of FS compared with GS was mainly attributable to CHD and was opposed to the difference in other heart disease (OHD). When $\mathrm{CHD}$ and $\mathrm{OHD}$ are added up, the overall difference between FS and GS is about $10 \%$, which corresponds approximately to the difference in stroke mortality in men. GS had significantly higher mortality rates due to COPD (both genders), stomach cancer (only men) and breast cancer (women). In contrast, men and women in FS had significantly higher mortality due to illdefined causes, UADT and lung cancer, while rates for liver cirrhosis and liver cancer were higher in men only. Only minor differences between regions were found for suicide, transport accidents, intestinal and prostate cancer.

\section{Risk factors in Swiss regions (from the SHS)}

Figure 1 shows the prevalence of risk factors. Except for obesity, where there were no significant differences, all risk factors were more frequent in FS than in GS and the differences tended to be larger in women than in men. The largest differences between the regions were found for daily alcohol consumption. This difference was particularly pronounced in women. The 
Table 1 Number of deaths, mortality rate per 100000 person years with $95 \%$ Cls by region, for selected causes of deaths

\begin{tabular}{|c|c|c|c|c|}
\hline & \multicolumn{2}{|c|}{ German Switzerland } & \multicolumn{2}{|c|}{ French Switzerland } \\
\hline & Deaths & Rate $(95 \% \mathrm{CI})$ & Deaths & Rate $(95 \% \mathrm{CI})$ \\
\hline \multicolumn{5}{|l|}{ Men } \\
\hline All causes & 85207 & $1115.4(1107.9$ to 1122.8$)$ & 27570 & 1164.0 (1150.3 to 1177.6$)$ \\
\hline All circulatory & 29479 & 382.7 (378.4 to 387.1 ) & 8085 & 338.3 (330.9 to 345.7 ) \\
\hline Coronary heart disease & 16911 & 220.0 (216.7 to 223.4$)$ & 3885 & 163.1 (158.0 to 168.2 ) \\
\hline Other heart disease & 5526 & 72.0 (70.2 to 73.9$)$ & 2271 & 95.1 (90.7 to 99.1 ) \\
\hline Stroke & 3613 & 46.3 (44.8 to 47.8$)$ & 1007 & 41.7 (39.1 to 44.3$)$ \\
\hline All cancer & 31957 & 419.8 (415.2 to 424.4$)$ & 11181 & 473.4 (464.6 to 482.2 ) \\
\hline UADT cancer & 2735 & 36.7 (34.9 to 38.4 ) & 1365 & 59.2 (56.3 to 62.0$)$ \\
\hline Stomach cancer & 1517 & 19.9 (18.9 to 20.9$)$ & 392 & 16.6 (14.9 to 18.2 ) \\
\hline Intestinal cancer & 3262 & 42.7 (41.2 to 44.2 ) & 1072 & 45.3 (42.6 to 48.1 ) \\
\hline Liver cancer & 1149 & $15.1(14.3$ to 16.0$)$ & 630 & 26.7 (24.6 to 28.8$)$ \\
\hline Lung cancer & 9449 & $124.6(122.1$ to 127.1$)$ & 3350 & $142.3(137.5$ to 147.1$)$ \\
\hline Prostate cancer & 2845 & 36.1 (34.8 to 37.5$)$ & 861 & 34.8 (32.5 to 37.2 ) \\
\hline All other diseases & 9856 & $128.7(126.4$ to 131.3$)$ & 3168 & $132.9(128.6$ to 137.4$)$ \\
\hline COPD & 3408 & $43.7(42.2$ to 45.1$)$ & 775 & 31.8 (29.6 to 34.1$)$ \\
\hline Liver cirrhosis & 2120 & 28.4 (27.2 to 29.6$)$ & 966 & 41.9 (39.2 to 44.5$)$ \\
\hline ill-defined & 2070 & 27.5 (26.3 to 28.7$)$ & 1335 & 56.8 (53.7 to 59.8 ) \\
\hline All injuries & 6317 & 84.5 (82.4 to 86.6$)$ & 2060 & 88.8 (85.0 to 92.7 ) \\
\hline Suicide & 3092 & 41.5 (40.1 to 43.0$)$ & 981 & 42.6 (39.9 to 45.2 ) \\
\hline Transport accident & 1058 & $14.2(13.3$ to 15.0$)$ & 360 & 15.6 (14.0 to 17.2$)$ \\
\hline \multicolumn{5}{|l|}{ Women } \\
\hline All causes & 49125 & 552.3 (547.2 to 557.0$)$ & 14880 & 529.6 (521.0 to 538.2 ) \\
\hline All circulatory & 12929 & 137.2 (134.8 to 139.6$)$ & 3624 & 121.9 (117.9 to 126.0$)$ \\
\hline Coronary heart disease & 5630 & 59.2 (57.6 to 60.7$)$ & 1300 & 43.0 (40.6 to 45.3$)$ \\
\hline Other heart disease & 2699 & $29.0(27.1$ to 30.4$)$ & 1201 & 40.8 (38.9 to 43.0$)$ \\
\hline Stroke & 2627 & 27.8 (26.7 to 28.9$)$ & 681 & 23.1 (21.3 to 24.9$)$ \\
\hline All cancer & 22780 & 263.4 (259.9 to 266.8$)$ & 6985 & 255.1 (249.0 to 261.1 ) \\
\hline UADT cancer & 549 & $6.5(6.0$ to 7.1$)$ & 254 & 9.4 (8.4 to 10.8 ) \\
\hline Stomach cancer & 713 & $8.0(7.4$ to 8.6$)$ & 214 & 7.7 (6.7 to 8.7$)$ \\
\hline Intestinal cancer & 2195 & 24.8 (23.7 to 25.8$)$ & 650 & 23.1 (21.3 to 24.9$)$ \\
\hline Liver cancer & 375 & 4.2 (3.8 to 4.6$)$ & 138 & $5.0(4.2$ to 5.9$)$ \\
\hline Lung cancer & 2535 & 30.0 (28.8 to 31.2$)$ & 987 & 36.4 (34.1 to 38.7 ) \\
\hline Breast cancer & 5600 & 67.1 (65.3 to 68.9$)$ & 1621 & 61.4 (58.4 to 64.4$)$ \\
\hline All other diseases & 7533 & 82.6 (80.8 to 84.6$)$ & 2056 & 70.8 (67.6ç73.9) \\
\hline COPD & 1311 & $14.2(13.4$ to 15.0$)$ & 304 & $10.4(9.2$ to 11.6$)$ \\
\hline Liver cirrhosis & 981 & 12.2 (11.4 to 12.9$)$ & 347 & 13.4 (11.9 to 14.8$)$ \\
\hline III-defined & 938 & $10.9(10.2$ to 11.6$)$ & 663 & 24.1 (22.3 to 26.0$)$ \\
\hline All injuries & 2653 & 31.9 (30.7 to 33.1$)$ & 901 & 33.9 (31.7 to 36.2 ) \\
\hline Suicide & 1335 & 16.6 (15.7 to 17.5$)$ & 447 & 17.4 (15.8 to 19.0$)$ \\
\hline Transport accident & 352 & 4.2 (3.8 to 4.7$)$ & 149 & 5.5 (4.7 to 6.4$)$ \\
\hline
\end{tabular}

Swiss National Cohort 1990-2000, $n=1862776$ (age $=45-74$ years).

COPD, chronic obstructive pulmonary disease; UADT, upper aerodigestive tract.

ICD codes of causes of death see table A1 (online).

Rates were standardised to the WHO standard population "Europe". ${ }^{10}$

Data source: Swiss Federal Statistical Office/Swiss National Cohort.

difference in less-than-good health between FS and GS was not statistically significant in men.

\section{Differences in mortality between in Swiss regions and between France and Germany between 1980 and 2000}

In men, between 1980 and 2000, all-cause mortality decreased between by $-30 \%$ (France) and by $-38 \%$ (French Switzerland). For most causes, the decrease was a bit stronger in the Swiss regions than in Germany and France. The most pronounced decrease could be observed for circulatory diseases in FS $(-59 \%$ in 20 years), although accompanied by the fastest increase in ill-defined causes. In women, the decrease in all-cause mortality was more similar in regions and countries (between $-30 \%$ and $-33 \%)$. While the decrease in cancer mortality was identical in GS and Germany (-18\%), it was stronger in FS (-22\%) than in France (-10\%).
Figure 2 shows the proportions of selected causes of death between 1980 and 2000 in France, FS, GS and Germany respectively within four broad groups (circulatory diseases, cancer, other diseases, external causes). Although most absolute mortality rates showed a clearly decreasing trend, generally the relative ranking of the single causes of death persisted over time. For details see table A3 (available online).

Figure 3 contrasts on a logarithmic scale the ratio between mortality rates from FS and GS with that from France and Germany. Values above 1 mean that rates were larger in FS and France than in GS and Germany respectively. Values below 1 mean the opposite. Generally the ratios between FS and GS were smaller (except for liver cirrhosis in men and UADT and liver cancer in women) than those between France and Germany. Ratios between regions and countries run in the opposite direction in women for lung cancer, in men for 

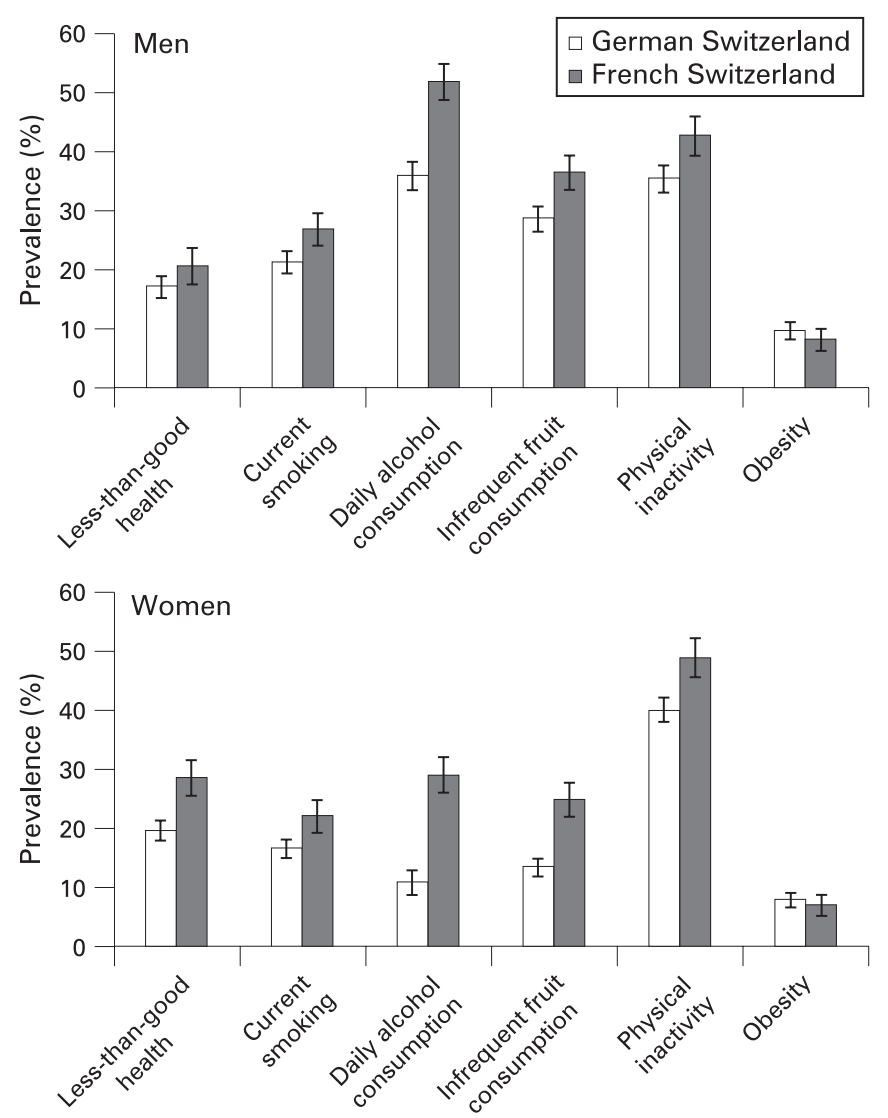

Figure 1 Prevalence of risk factors (weighted proportion with $95 \% \mathrm{CI}$ ), Swiss Health Survey 1992/3 ( $n=5739$; age $=45-74$ years). Data source: Swiss Federal Statistical Office, Swiss Health Survey 1992/3.

intestinal cancer and in both sexes for liver cirrhosis and for OHD. The largest difference in rate ratios between regions and countries was found for OHD (men and women), liver cirrhosis in men and lung and stomach cancer in women.

From figs 2 and 3 three broad groups of causes of death applying to both genders can be differentiated:

- Consistent gradient between French- and German-speaking areas (Swiss regions and countries): CHD, cancers of UADT and liver (women only adumbrated); COPD.

- Gradient between FS and GS but not between countries: $\mathrm{OHD}$, breast cancer, liver cirrhosis (preponderantly males); lung cancer shares this pattern only in men whereas in women there is also a gradient between France and Germany, but in the opposite direction.

- No (or small) gradient between FS and GS: stroke and transport accidents (both with a tendency towards group 1); suicide, stomach, intestinal and prostate cancer.

\section{DISCUSSION}

In this study we examined mortality rates in the French and German part of Switzerland and compared them with associated risk factors and SRH and with corresponding figures from France and Germany. In several respects, Switzerland mirrored international patterns. Deaths from CHD, stroke and COPD were more common in GS and Germany, while causes related to alcohol consumption were more prevalent in FS and France. Mortality from injuries was higher in France than in Germany while there was only a tendency for higher rates in FS than in GS. For most causes, mortality differences were larger between countries than between Swiss regions. Not in line with differences between Swiss regions were OHD and liver cirrhosis (both sexes) and lung cancer (women). Mortality differences between FS and GS were only poorly explained by physical inactivity, obesity and infrequent fruit consumption.

Little agreement could be observed between the proportion of those with less-than-good SRH and mortality patterns: FS women more often rated their health as less than good, despite lower allcause mortality. This may be explained by a comparably more pessimistic perception of own health status, which is a common feature of the French and other romance language areas. ${ }^{11}{ }^{12}$

Mortality from CHD and stroke was higher in the Germanspeaking areas than in the French-speaking areas but with much larger difference between countries than between the two Swiss regions. These larger differences are in accordance with the higher prevalence of obesity and infrequent vegetable consumption in Germany but at odds with the similar smoking prevalence in both countries and with more physical activity in Germany. ${ }^{13}{ }^{14}$ In our comparison, lower mortality from $\mathrm{CHD}$ and stroke in FS cannot be explained by a lower prevalence of obesity, smoking, physical inactivity or infrequent fruit consumption since these differences were either marginal or went in the opposite direction (fig 1). However, more frequent alcohol consumption is likely to contribute to the lower CHD mortality in FS and France. The protective effect of alcohol appears to be particularly strong in the framework of a healthy lifestyle, as exists in many French-speaking regions. ${ }^{15-17}$ Nevertheless, larger international than regional differences in CHD cannot entirely be explained by risk factors. Most likely, nationally different assignment of causes of death leads to an underestimation of $\mathrm{CHD}$ in France and one could expect that differences between France and Germany would be closer to those found between FS and GS if assignment practice was more similar between the three countries. In fact, a population-based autopsy study showed that death cases from circulatory diseases were overregistered in mortality statistics in Germany. ${ }^{18}$ In contrast, comparisons of official rates with figures from the MONICA (MONItoring of Trends and Determinants in CArdiovascular Disease) study as well as international comparisons suggest that mortality rates of CHD are underestimated in France. ${ }^{5} 19$

In both sexes, higher smoking prevalence in FS was mirrored by higher lung cancer rates. The opposite pattern found between countries (higher lung cancer mortality in Germany) is probably due to different stages in the smoking epidemic. ${ }^{20}$ COPD rates were higher in both German-speaking areas despite lower smoking prevalence. ${ }^{14} \mathrm{~A}$ part of this conflicting pattern may be due to different assignment. The diagnostic validity of COPD may be relatively poor. In fact, international differences in COPD mortality could not be explained by differences in smoking. ${ }^{21}$ In French-speaking regions, COPD appears to be assigned rather reluctantly. ${ }^{21} 22$

Cancers of the UADT and the liver were more frequent in France than in Germany and in FS than in GS. Alcohol consumption, as a major risk factor was higher in the two French-speaking areas than in the German-speaking areas (fig 1 and Cavelaars $\mathrm{et} \mathrm{a}^{14}$ ). Accordingly, the rates for liver cirrhosis in men and women were lower in GS than in FS. However, on the international level rates for liver cirrhosis are reversed with higher rates in Germany than in France. Type of alcohol, obesity and nutritional aspects other than alcohol (eg, pork meat, infrequent fruit and vegetable consumption) may play a role in the development of liver cirrhosis, ${ }^{23-25}$ while viral hepatitis is unlikely to have a major impact. ${ }^{25}$ Nevertheless, known risk factors are unlikely to explain the large difference between Germany and GS. Based on the logical constellation of mortality from liver cirrhosis in France, FS and GS, the high rates in Germany must be regarded 

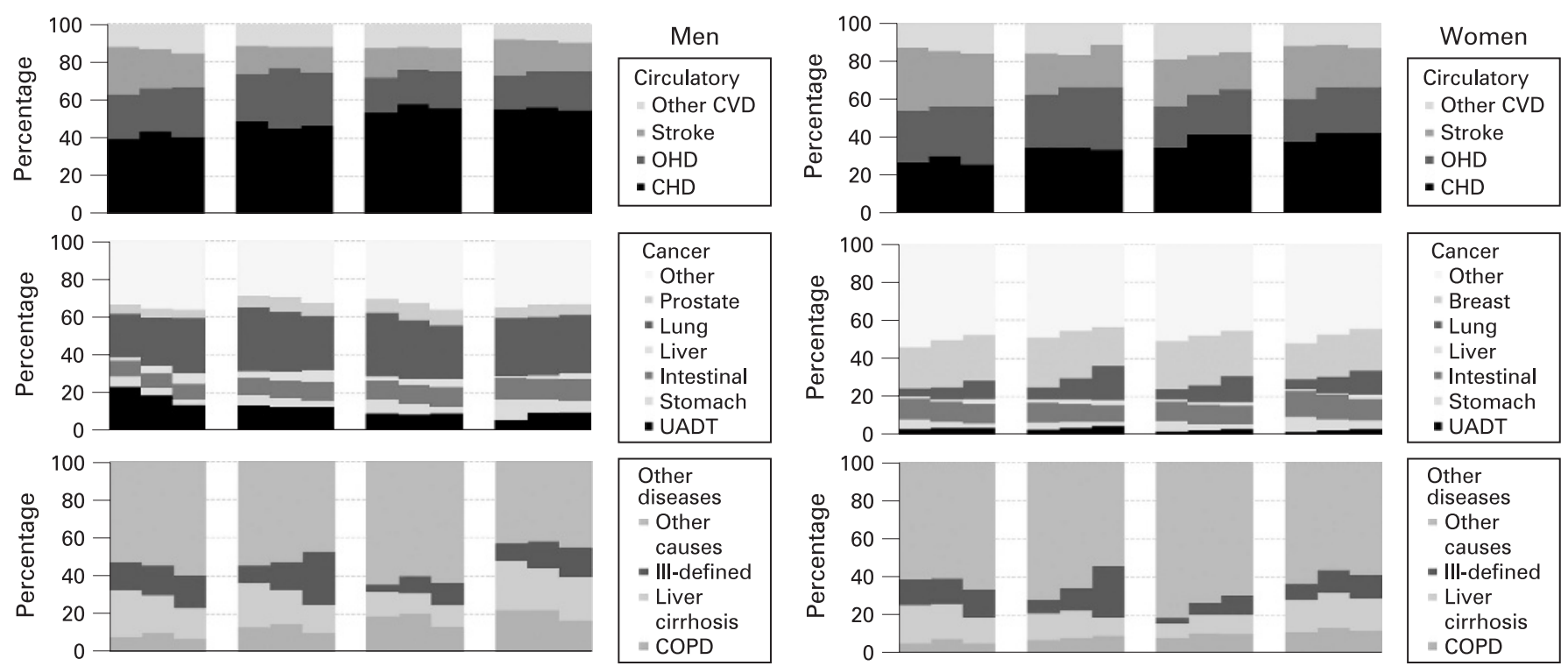

Other



diseases

= Other

causes

- Ill-defined

- Liver

cirrhosis

$=$ COPD
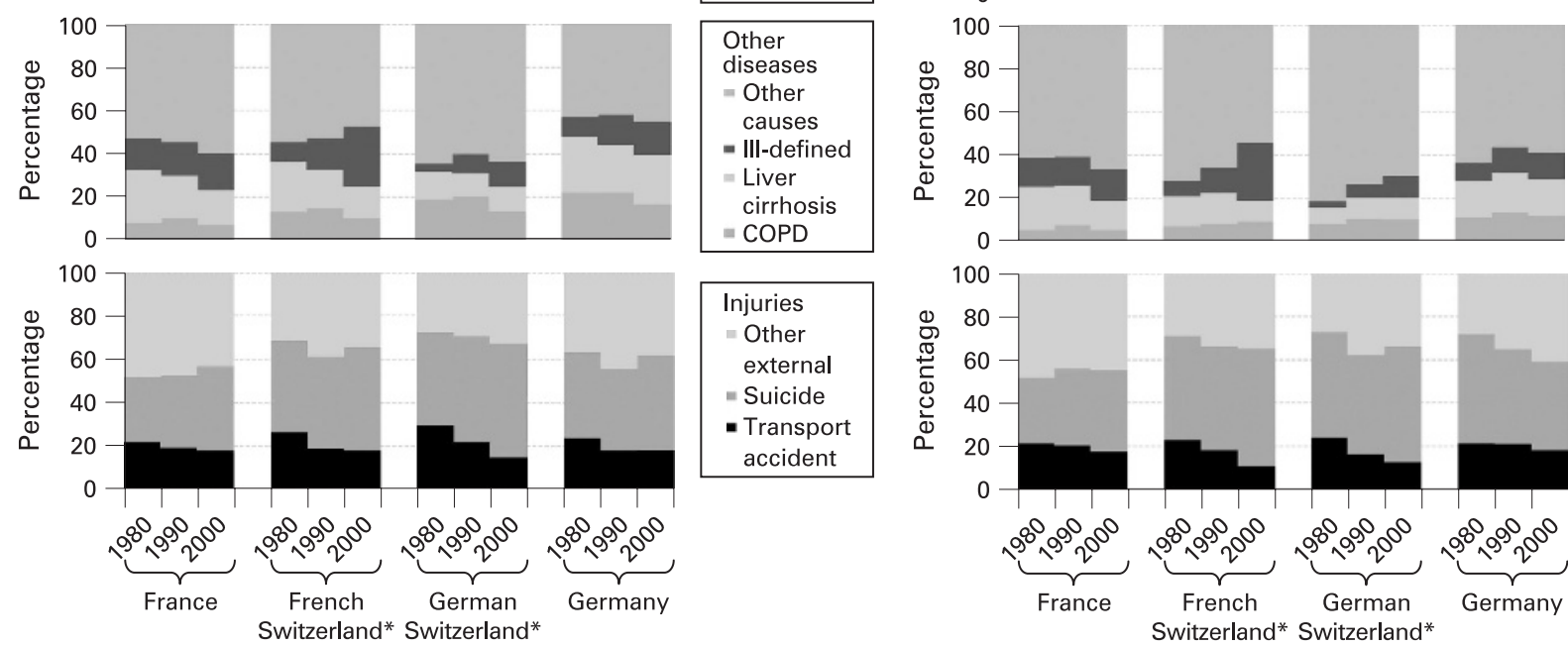

Other

diseases

= Other

causes

- III-defined

$=$ Liver

cirrhosis

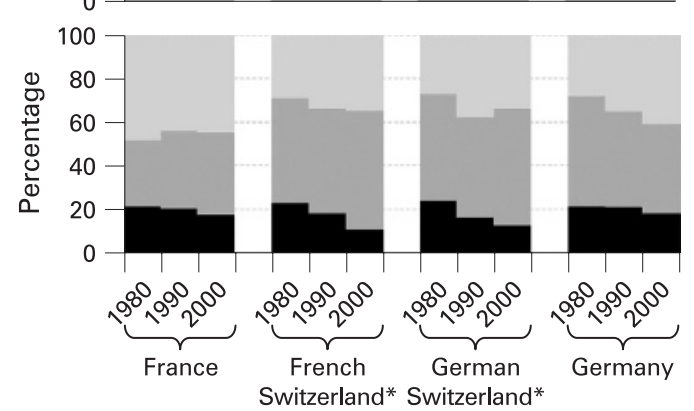

- COPD

Figure 2 Proportion of causes of death as a percentage of group total based on age-standardised mortality rates (deaths per 100000 population; age $=45-74$ years) in 1980, 1990 and 2000. UADT, upper aerodigestive tract; COPD, chronic obstructive pulmonary disease. Rates were standardised to the WHO standard population "Europe". ${ }^{10}$ Data source: WHO Mortality Database (http://www.who.int/whosis/mort/download/en/index.html) and Swiss Federal Statistical Office, mortality statistics. For corresponding mortality rates see table A3 (available online). Mortality rates from Germany from 1980 and 1990 refer to West Germany. ${ }^{*} 1980: 1979-1982$; 1990:1989-1992; 2000: 1999-2002.

as unexplained and as a challenge for further investigation. The larger rates for stomach cancer found in GS and Germany than in FS and France may root in different traditional diets with more processed meat in German-speaking areas and more fruits and vegetables in French speaking areas. ${ }^{26}{ }^{27}$ Higher consumption of processed meat and lower fruit and vegetable consumption in Germany than in GS (1961-1980) are likely to explain the larger difference between countries. ${ }^{28}$ However, one can speculate whether differences between regions and countries will decrease or even disappear over time.

Injuries (suicide and transport accidents) were more frequent in the French-speaking populations, but with generally smaller differences within Switzerland than between France and Germany. This probably reflects different national legislation concerning road traffic and possession of firearms. ${ }^{29-31}$ Cultural differences in risk perception and behaviour (eg, patterns of alcohol consumption, adherence to speed limits, seatbelt use) could explain the higher mortality from transport accidents in French-speaking areas. ${ }^{30} 32$

Some international variation in mortality (eg, OHD and stroke) could not be explained by the Swiss comparison and could be rooted, among other causes, in different healthcare systems. However, in this respect, there are various similarities between Germany and France (eg, similar per capita health expenditures, almost full insurance coverage, similarly high satisfaction). ${ }^{33-35}$ In fact, medical care per se has only limited impact on mortality when other health determinants are considered. Lifestyle factors have a much stronger influence on disease incidence, particularly on cancer incidence. ${ }^{36}{ }^{37}$ Thus, policies to promote disease prevention are likely to have a large potential for mortality reduction, especially in countries with highly developed healthcare systems. In this respect, France with its centralistic system may have an advantage over Germany with its federal system. For example, a smoking ban has been rapidly implemented on a nationwide level in France, but not in Germany. ${ }^{38}$ Moreover, national differences in assignment of causes of death may be more important than expected. This may especially be the case for mortality from COPD, liver cirrhosis, CHD versus $\mathrm{OHD}$ and ill-defined causes. ${ }^{5122} 39$ A part of the variation between countries and regions (eg, smoking epidemic and lung cancer in FS and French women) could be due to different stages in the health transition. Trends (see online table A3) suggest that France and Germany will achieve current Swiss mortality rates for some causes in the next one to two decades, eg, lung, UADT and stomach cancer, liver cirrhosis, stroke and transport accidents.

\section{Limitations}

Comparisons between risk factors and mortality should be interpreted cautiously. Most risk factors impact with a latency of 20 years or more on mortality. Thus, simultaneous assessments of mortality and risk factors only roughly reflect real associations. Also, on a population base, only cross-sectional (1992/3) data on risk factors were available, precluding interpretation of trends in 
Figure 3 Mortality rate ratios French versus German Switzerland (grey, 19902000) and France versus Germany (black, average of 1990 and 2000), age $=45-74$ years. CHD, coronary heart disease; COPD, chronic obstructive pulmonary Swiss Federal Statistical Office/Swiss National Cohort, mortality statistics (French vs German Switzerland); WHO mortality database (France vs Germany). Mortality rates from Germany from 1990 refer to West Germany. ns: difference not statistically significant $(p>0.05)$ between French and German Switzerland or between France and Germany respectively. disease; OHD, other heart disease; UADT, upper aerodigestive tract. Data sources:
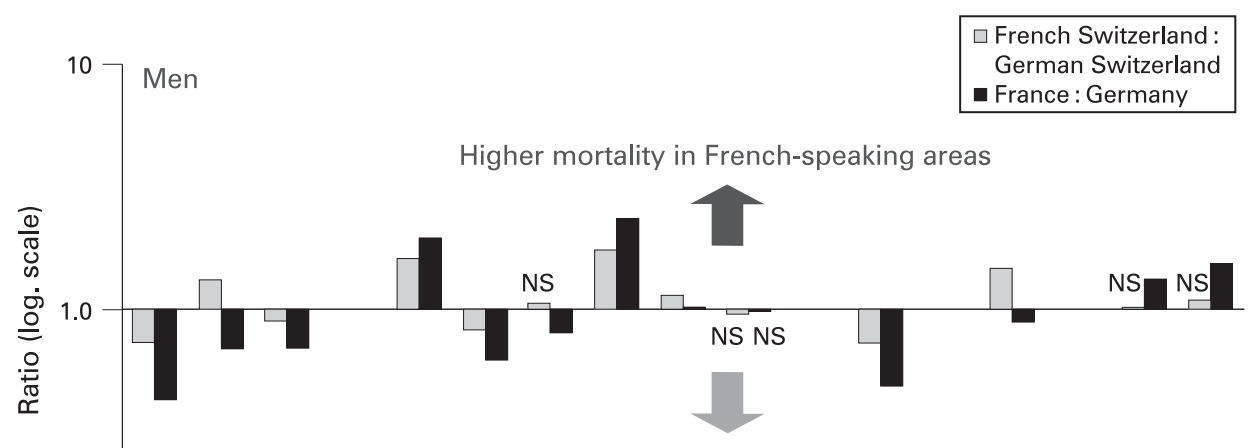

Higher mortality in German-speaking areas

0.1
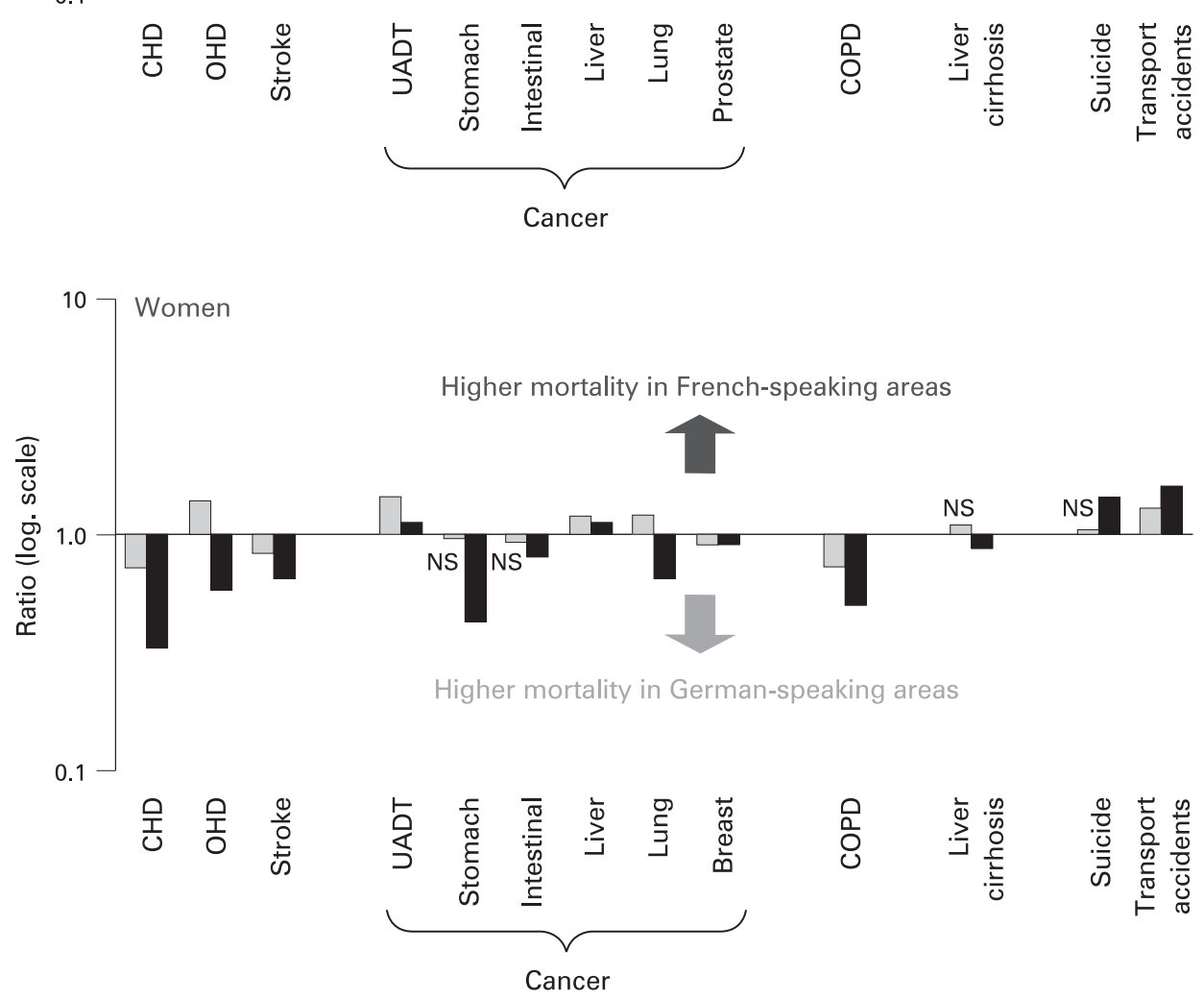

risk factors. However, comparisons with earlier (1977) and later (2002) surveys suggest that many major risk factors remained quite stable in the Swiss population. ${ }^{40}{ }^{41}$ Another limitation for comparison is coverage. The SNC covers the whole population and is based on mandatory data collection (census, vital statistics), whereas the SHS is a $3 \%$ sample with a participation rate of $71 \%$. Persons with an unhealthy lifestyle or belonging to lower socioeconomic groups are likely to be under-represented in health surveys. ${ }^{42}$ Causes of death not only depend on risk factors but also on practices of assigning diagnoses. ${ }^{35}$ This is well known, for example for ill-defined causes of death. ${ }^{43}{ }^{44}$ In fact, the large variations in ill-defined causes over time, particularly in FS, is unlikely to reflect real changes. Probably cultural differences also exist in reporting desirable behaviours such as fruit consumption or physical activity. ${ }^{45}{ }^{46}$ Also our equation of Germany with GS and France with FS has limited validity because these large countries are inhomogeneous. With respect to Germany and France we had to rely on cross-sectional data which have inherent limitations. Finally, to precisely delineate potentials for further reduction in mortality it would be essential to consider social inequalities in mortality and corresponding risk factors.

\section{CONCLUSION}

Various characteristic differences between France and Germany have parallels in variations between French and German Switzerland. However, this comparison also revealed magnitudes and differences in mortality (eg, stomach and lung cancer, COPD, liver cirrhosis, ill-defined causes, $\mathrm{OHD}$ and $\mathrm{CHD}$ ) that could not be explained by risk factors or national healthcare systems. Given the high completeness and quality of the data, the analysis of regional differences in Switzerland has the potential to separate real differences from those due to weaknesses or peculiarities in national assignment practices. When used judiciously, Swiss data can help to identify fields for public health interventions and to anticipate future developments in France and Germany.

Acknowledgements: We thank the Swiss Federal Statistical Office for having enabled the construction of the Swiss National Cohort and for providing data from the Swiss Health Survey 1992/93 and from the mortality statistics 1979-2002. The comparison between France and Germany is based on material drawn from the Mortality Database of the World Health Organization.

Funding: We thank the Swiss National Science Foundation for supporting this study (grant 33CSC0-108806). 


\section{What is already known on this subject}

- Among European countries substantial differences in causes of death can be found.

- There is a lack of international data allowing comparisons of trends in risk factors and mortality.

- It is unclear how much international variations are due to differences in risk factors, national health policies, statistical systems or peculiarities in assignment of causes of death.

\section{What this study adds}

- Switzerland's language regions allow cultural influences to be explored without bias due to differences in national health policies and statistical systems.

- We found characteristic differences in mortality between French and German Switzerland, many of them being similar to those between France and Germany.

- Some variation in mortality between the two countries could not be explained by the Swiss regional comparison nor by risk factors. Possible explanations include differences in assignment practices or different health transition stages of countries and regions.

- Swiss data may help to elucidate unexplained discrepancies in mortality.

\section{Competing interests: None.}

The members of the Swiss National Cohort Study Group are Felix Gutzwiller (Chairman of Executive Board), Matthias Bopp (both Zurich), Matthias Egger (Chairman of Scientific Board), Adrian Spoerri, Malcolm Sturdy (Data manager) and Marcel Zwahlen (all Bern), Charlotte Braun-Fahrländer (Basell), Fred Paccaud (Lausanne) and André Rougemont (Geneva).

\section{REFERENCES}

1. Mackenbach JP, Stirbu I, Roskam AJ, et al. Socioeconomic inequalities in health in 22 European countries. N Engl J Med 2008;358(23):2468-81.

2. Mackenbach JP. Health inequalities: Europe in profile-An independent, expert report commissioned by the UK Presidency of the EU. Rotterdam: Dept. of Public Health, Erasmus MC, 2006:41.

3. Kattainen A, Salomaa V, Harkanen T, et al. Coronary heart disease: from a disease of middle-aged men in the late 1970s to a disease of elderly women in the 2000s. Eur Heart J 2006;27:296-301.

4. Lindeboom M, van Doorslaer E. Cut-point shift and index shift in self-reported health. $J$ Health Econ 2004;23:1083-99.

5. Lozano R, Murray CJL, Lopez AD, et al. Miscoding and misclassification of ischaemic heart disease mortality. Global Programme on Evidence for Health Policy. Working Paper No. 12. WHO, 2001

6. Bopp M, Spoerri A, Zwahlen M, et al. Cohort Profile: The Swiss National Cohort-a longitudinal study of 6.8 million people. Int J Epidemiol 2009;38:379-84.

7. Bundesamt für Statistik. Eidgenössische Volkszählung 2000. Abschlussbericht zur Volkszählung 2000. Neuchâtel, 2005.

8. Bopp M, Gutzwiller F. Die Swiss National Cohort 1990-2000-eine soziodemografische Datenbasis für longitudinale Gesundheitsanalysen. Swiss National Cohort Report Nr. 5, Forschung und Dokumentation 30. Zürich: Institut für Sozial- und Präventivmedizin, 2007.

9. Eichholzer M, Bisig B. Daily consumption of (red) meat or meat products in Switzerland: results of the 1992/93 Swiss Health Survey. Eur J Clin Nutr 2000;54(2):136-42.

10. Day NE. Cumulative Rate and Cumulative Risk. In: Waterhouse JAH, MC, Shanmugaratnam K, Powell J, eds. Cancer incidence in Five Continents (IARC Scientific Publications No. 42). Lyon: International Agency for Research on Cancer, 1982:668-70.

11. Jurges $\mathbf{H}$. True health vs response styles: exploring cross-country differences in selfreported health. Health Econ 2007:16(2):163-78.

12. DeSalvo KB, Bloser N, Reynolds K, et al. Mortality prediction with a single general self-rated health question. A meta-analysis. J Gen Intern Med 2006;21(3):267-75

13. Steptoe A, Wardle J, Fuller R, et al. Leisure-time physical exercise: prevalence, attitudinal correlates, and behavioral correlates among young Europeans from 21 countries. Prev Med 1997:26:845-54.

14. Cavelaars $\mathbf{A E}$, Kunst A, Mackenbach J. Socio-economic differences in risk factors for morbidity and mortality in the European Community. J Health Psychology 1997:2:353-72

15. Marques-Vidal P, Montaye M, Arveiler D, et al. Alcohol consumption and cardiovascular disease: differential effects in France and Northern Ireland. The PRIME study. Eur J Cardiovasc Prev Rehabil 2004;11:336-43.
16. Breslow RA, Graubard BI. Prospective study of alcohol consumption in the United States: quantity, frequency, and cause-specific mortality. Alcohol Clin Exp Res 2008;32:513-21.

17. Mukamal KJ, Chiuve SE, Rimm EB. Alcohol consumption and risk for coronary heart disease in men with healthy lifestyles. Arch Intern Med 2006:166:2145-50.

18. Modelmog D, Rahlenbeck S, Trichopoulos D. Accuracy of death certificates: a population-based, complete-coverage, one-year autopsy study in East Germany. Cancer Causes Control 1992;3:541-6.

19. Tunstall-Pedoe H, Kuulasmaa K, Amouyel P, et al. Myocardial infarction and coronary deaths in the World Health Organization MONICA Project. Registration procedures, event rates, and case-fatality rates in 38 populations from 21 countries in four continents. Circulation 1994;90:583-612.

20. Mackenbach JP, Huisman M, Andersen 0, et al. Inequalities in lung cancer mortality by the educational level in 10 European populations. Eur J Cancer 2004;40(1):126-35.

21. Brown CA, Crombie IK, Tunstall-Pedoe $\mathrm{H}$. Failure of cigarette smoking to explain international differences in mortality from chronic obstructive pulmonary disease. J Epidemiol Community Health 1994;48(2):134-9.

22. Schüler G, Bopp M. Chronische Bronchitis, Emphysem, Asthma. Atlas der Krebsmortalität in der Schweiz 1970-1990, Teil B. Basel: Birkhäuser, 1997:99-102.

23. Bode C, Bode JC, Erhardt JG, et al. Effect of the type of beverage and meat consumed by alcoholics with alcoholic liver disease. Alcohol Clin Exp Res 1998;22:1803-5.

24. Festi D, Colecchia A, Sacco T, et al. Hepatic steatosis in obese patients: clinical aspects and prognostic significance. Obes Rev 2004;5(1):27-42.

25. Bosetti C, Levi F, Lucchini F, et al. Worldwide mortality from cirrhosis: an update to 2002. J Hepatol 2007;46:827-39

26. Gonzalez CA, Jakszyn P, Pera G, et al. Meat intake and risk of stomach and esophageal adenocarcinoma within the European Prospective Investigation Into Cancer and Nutrition (EPIC). J Natl Cancer Inst 2006;98:345-54.

27. Kono S, Hirohata T. Nutrition and stomach cancer. Cancer Causes Control 1996; 7(1):41-55

28. Food and Agriculture Organization of the United Nations (FAO), Food Balance Sheets [http://faostat.fao.org/site/609/default.aspx\#ancor]. 2008.

29. Ajdacic-Gross V, Killias M, Hepp U, et al. Changing times: a longitudinal analysis of international firearm suicide data. Am J Public Health 2006;96:1752-5.

30. Steptoe A, Wardle J, Fuller R, et al. Seatbelt use, attitudes, and changes in legislation: an international study. Am J Prev Med 2002;23(4):254-9.

31. Richter ED, Berman T, Friedman L, et al. Speed, road injury, and public health. Annu Rev Public Health 2006;27:125-52.

32. Sivak M, Soler J, Trankle U, et al. Cross-cultural differences in driver risk-perception. Accid Anal Prev 1989;21:355-62.

33. van Doorslaer E, Masseria C. Income-Related Inequality in the Use of Medical Care in 21 OECD Countries OECD Health Working Paper No. 142004

34. Heijink R, Noethen M, Renaud T, et al. Cost of illness: an international comparison. Australia, Canada, France, Germany and The Netherlands. Health Policy 2008;88(1):49-61

35. Green DG, Irvine B. Health Care in France and Germany: Lessons for the UK. London, England: Civitas: Institute for the Study of Civil Society, 2001.

36. Mokdad AH, Marks JS, Stroup DF, et al. Actual causes of death in the United States, 2000. Jama 2004;291:1238-45.

37. Wen CP, Tsai SP, Chung WS. A 10-year experience with universal health insurance in Taiwan: measuring changes in health and health disparity. Ann Intern Med 2008;148(4):258-67.

38. Renaud T, Blum K. Ban on smoking in France: a new step forward; Ban on smoking in Germany: a never ending story?! [http://www.hpm.org]. Health Policy Monitor: Bertelsmann Stiftung, 2008.

39. Jougla $\mathbf{E}$, Pavillon $\mathrm{G}$, Rossollin $\mathrm{F}$, et al. Improvement of the quality and comparability of causes-of-death statistics inside the European Community. EUROSTAT Task Force on "causes of death statistics". Rev Epidemiol Sante Publique 1998:46:447-56.

40. Gutzwiller F, Nater B, Martin J. Community-based primary prevention of cardiovascular disease in Switzerland: methods and results of the National Research Program (NRP 1A). Prev Med 1985;14:482-91.

41. Eichholzer M, Bernasconi F, Jordan P, et al. Ernährung in der Schweiz 2002Resultate der Schweizerischen Gesundheitsbefragung. Schweiz Rundsch Med Prax 2005;94:1713-21

42. Jousilahti P, Salomaa V, Kuulasmaa K, et al. Total and cause specific mortality among participants and non-participants of population based health surveys: a comprehensive follow up of 54372 Finnish men and women. J Epidemiol Community Health 2005;59:310-5.

43. D'Amico M, Agozzino E, Biagino A, et al. III-defined and multiple causes on death certificates - a study of misclassification in mortality statistics. Eur J Epidemiol 1999;15(2):141-8.

44. Schüler G, Bopp M. Ungenau vermerkte Todesursachen. Atlas der Krebsmortalität in der Schweiz 1970-1990, Teil B. Basel: Birkhäuser, 1997:129-35.

45. Klesges LM, Baranowski T, Beech B, et al. Social desirability bias in self-reported dietary, physical activity and weight concerns measures in 8- to 10-year-old AfricanAmerican girls: results from the Girls Health Enrichment Multisite Studies (GEMS). Prev Med 2004;38(Suppl):S78-87.

46. Hebert JR, Hurley TG, Peterson KE, et al. Social desirability trait influences on selfreported dietary measures among diverse participants in a multicenter multiple risk factor trial. J Nutr 2008;138(1):226S-234S. 